\title{
A Comparison between Different Management Surgical Approaches in the Treatment of Splenic Flexure Colon Cancer
}

\author{
Elsayed I. El-Hendawy ${ }^{1}$ Mohamed Farouk Amin ${ }^{1}$ Ahmed M. Fahmy ${ }^{2}$ Ahmed Z. Alattar ${ }^{3}$ \\ Shereen Elshorbagy ${ }^{4}$ Ola A. Harb ${ }^{5}{ }^{-0}$ Ahmed Fathy Gomaa ${ }^{6}$ Ahmed Embaby ${ }^{6}$ Ahmed M. Elsayed ${ }^{7}$ \\ Gamal Osman ${ }^{1}$ Ramadan M. Ali ${ }^{1}$
}

${ }^{1}$ Department of General Surgery, Faculty of Medicine, Zagazig University, Zagazig, Egypt

2 Department of Anesthesia and Intensive Care, Faculty of Medicine, Zagazig University, Zagazig, Egypt

${ }^{3}$ Department of Clinical Oncology and Nuclear Medicine, Faculty of Medicine, Zagazig University, Zagazig, Egypt

${ }^{4}$ Department of Medical Oncology, Zagazig University Faculty of Medicine, Zagazig University, Zagazig, Egypt

${ }^{5}$ Department of Pathology, Zagazig University Faculty of Medicine, Zagazig University, Zagazig, Egypt

${ }^{6}$ Department of Internal Medicine, Faculty of Medicine, Zagazig University, Zagazig, Egypt

${ }^{7}$ Department of Tropical Medicine, Faculty of Medicine, Zagazig

University, Zagazig, Egypt

J Coloproctol 2022;42(1):47-53.
Address for correspondence Ola A. Harb, MD, PhD, Department of General Surgery, Faculty of medicine, Zagazig University, Zagazig, 44519, Egypt (e-mail: olaharb2015@gmail.com).

\section{Abstract \\ Keywords \\ - splenic flexure cancer \\ - surgery \\ - segmental resection \\ - outcome}

Background There are many surgical approaches which described extent of resection of the colon for adequate surgical management of splenic flexure cancer, but up till now there is no established surgical procedure, this is because the presence of double lymphatic drainage of the mesenteric vessels. Segmental resection of the colon for the management of splenic flexure cancer was a recently accepted surgical procedure. Objective In the present study, we aimed to compare three surgical management techniques to clarify the best management approach of Egyptian patients with splenic flexure cancer regarding operative, clinical, and oncological outcomes: segmental resection, and extended left or right hemicolectomy,.

Materials and Methods In the present study, we included 90 patients with splenic flexure cancer. Cases were divided into 3 groups. Each group included 30 patients in order to compare three surgical techniques: segmental resection, extended left hemicolectomy, and extended right hemicolectomy.

Results We have found no statistically significant differences between the three included groups regarding operative findings, postoperative complications, local recurrence, distant recurrence, disease progression, recurrence-free survival rate, progression-free survival rate, and overall survival rate. The operative time was longer, received

March 20, 2021

accepted after revision

August 6, 2021

published online

January 31, 2022
DOI https://doi.org/

10.1055/s-0041-1740201. ISSN 2237-9363. (c) 2022. Sociedade Brasileira de Coloproctologia. All rights reserved.

This is an open access article published by Thieme under the terms of the Creative Commons Attribution-NonDerivative-NonCommercial-License, permitting copying and reproduction so long as the original work is given appropriate credit. Contents may not be used for commercial purposes, or adapted, remixed, transformed or built upon. (https://creativecommons.org/ licenses/by-nc-nd/4.0/)

Thieme Revinter Publicações Ltda., Rua do Matoso 170, Rio de Janeiro, RJ, CEP 20270-135, Brazil 
and the number of lymph nodes was higher in the extended right hemicolectomy group

$(p<0.001)$.

Conclusion We have shown that segmental resection of the splenic flexure is surgically and clinically suitable for the adequate management of operable cases of carcinoma of the splenic flexure.

\section{Introduction}

Splenic flexure cancer is a type of colon cancer that is located in the left corner of the colon, in the distal part of the transverse colon, or in the proximal part of the descending colon. It is considered a rare anatomical variant of colon cancer. ${ }^{1}$ It is diagnosed late in advanced stage, mostly with obstructive manifestations. ${ }^{2}$ There are many surgical approaches that describe the extent of resection of the colon for successive management of splenic flexure cancer, but there is no established surgical procedure due to double lymphatic drainage of the mesenteric vessels. ${ }^{3,4}$ Many authors tried to identify the best surgical approaches for the management of splenic flexure cancer, either open or laparoscopic, extracorporeal or intracorporeal anastomosis. ${ }^{2}$ Few surgeons accept the performance of segmental resection of the colon for the management of splenic flexure cancer. ${ }^{5,6}$

There are few published reports that assessed the benefits of segmental resection in comparison with extended colectomy to detect the best approach for the surgical management of splenic flexure cancer. Rega et al. ${ }^{1}$ tried in their retrospective study to detect the benefits of segmental resection and have showed similar oncological benefits from extended colectomy and segmental resection. To our knowledge, there are no prospective studies that compared the outcome of Egyptian patients with splenic flexure cancer who were managed by different surgical techniques.

In the present study, we aimed to compare three surgical management techniques to clarify the best management approach of Egyptian patients with splenic flexure cancer regarding operative, clinical and oncological outcomes: segmental resection, and extended left or right hemi-colectomy.

\section{Materials and Methods}

In the present study, we included 90 patients with splenic flexure cancer who were managed and subsequently followed-up in the period from February 2017 to February 2020. Cases were operated in General Surgery department of the Faculty of Medicine of the Zagazig University hospitals. Cases were divided into 3 groups. Each group included 30 patients in order to compare 3 surgical techniques: segmental resection, extended left hemicolectomy, and extended right hemicolectomy.

\section{Inclusion Criteria}

Patients with proven diagnosis of splenic flexure cancer stage I to III who underwent curative resection.

Patients with complete medical files.
Patients who accepted to be included in the study.

\section{Exclusion Criteria}

Patients with distant metastases, synchronous or metachronous colon cancer, palliative or emergency resection, and patients who received preoperative therapy were excluded.

Finally, we included ninety patients with splenic flexure cancer who were divided into 3 equal groups each group included 90 patients who were managed by one of the 3 different techniques.

\section{Preoperative Workup}

Complete physical examination, colonoscopy, biopsy for histopathological confirmation of the diagnosis, computed tomography (CT) of the whole body, and assessment of serum levels of carcinoembryonic antigen.

The following patient characteristics were recorded: age, gender, year of surgery, surgical management approach, and resection type

\section{Operative Data}

The following operative data were recorded: operative time, amount of blood loss, intraoperative complications, and operative mortality.

\section{Postoperative Data}

The following postoperative data were recorded: duration hospital stay, postoperative complications, 30-day morbidity and mortality.

\section{Histopathological Evaluation}

Histopathological subtype, grade, stage, number of dissected lymph nodes, and number of lymph nodes invaded by the cancer were recorded.

We used the $7^{\text {th }}$ edition of the American Joint Committee on Cancer for cancer staging. ${ }^{7}$

\section{Follow-up Data}

Most patients were followed-up for 3 years for the detection of disease recurrence, distant metastases, disease progression, progression-free survival, and overall survival rate. The end of the follow-up period was in February 2020.

The follow-up was performed every 4 months in the $1^{\text {st }}$ 2 years, then every 6 months in the $3^{\text {rd }}$ year.

Routine follow-up included complete physical examination and evaluation of the carcinoembryonic antigen.

Colonoscopy and whole-body CT were performed annually. 
In case of suspected metastasis or recurrence, positron emission tomography (PET-CT) scan, bone scan, and magnetic resonance imaging (MRI) were performed.

Local recurrence is defined by radiological and histopathological confirmation of cancer in the bowel wall or in the lymphatic drainage area in the site of the primary tumor.

Distant recurrence is defined by radiological and histopathological confirmation of cancer in the liver, the peritoneum, in nonregional lymph nodes, or in distant organs such as the lung or bone.

We calculated the progression-free survival rate from the time of surgery to the time of occurrence of recurrence of the tumor or of distant metastases. We calculated the overall survival rate from the time of surgery to the time of death of the patient.

Ethical approval was obtained from the local ethical committee of the Faculty of medicine of the Zagazig University.

Consent to be included in the present study was obtained from the included patients.

\section{Surgical Techniques}

All included patients have received antibiotics and antithrombotics as prophylactic perioperative therapies, but they have not received any mechanical preparation of the bowel.

For the group of patients who underwent extended right hemicolectomy, we have resected the ascending colon, the transverse colon, and part of the descending colon in addition to dissection of regional lymph nodes with ligation of the right colic, the ileocolic, the middle colic, and the left colic vessels at their origins. Then, we performed an ileocolic endto-side mechanical anastomosis.

For the group of patients who underwent extended left hemicolectomy, we have resected the segment of the colon located between the colorectal junction and the left third of the transverse colon, with excision of the regional lymph nodes, and performed ligation of the left branch of the middle colic and the inferior mesenteric vessels at their origins. We have restored intestinal continuity by mechanical colorectal side-to-end anastomosis. ${ }^{8,9}$

For the group of patients who underwent segmental splenic flexure resection, we have resected the colonic segment that is found between the distal part of the transverse colon and the first part of the descending colon. We have resected regional lymph nodes and ligated the left branch of the middle colic vessels, of the left colic vessels, and of the inferior mesenteric vein. ${ }^{10}$

We have restored intestinal continuity by mechanical colocolic side-to-end anastomosis

Usually, a mechanical side-to-end colocolic anastomosis was performed. We have resected the colon in addition to excision of the regional mesocolon. ${ }^{11}$

Patients with radiological preoperative confirmation of vascular or regional lymph nodes involvement by malignancy and patients with larger tumor size were more liable to undergo extended resection, either right or left. En-bloc resection of adjacent organs was performed in case of malignant or inflammatory involvement. ${ }^{12}$

\section{Statistical Analysis}

IBM SPSS Statistics for Windows version 24 (IBM Corp., Armonk, NY, USA0 was used for statistical analysis of the collected data. A $p$-value $\leq 0.05$ was considered as a statistically significant difference, and $p<0.001$ was considered highly significant. Kaplan and Meier survival curves were used to assess time to death and time to recurrence of the tumor.

\section{Results}

The present study included 90 patients who underwent surgical excision of splenic flexure cancer: we performed extended right hemicolectomy in 30 (33.3\%), extended left hemicolectomy in 30 (33.3\%), and segmental resection of the splenic flexure in 30 (33.3\%).

\section{Preoperative Results}

Demographics and basic findings about the patients are shown in - Table 1.

No statistically significant differences were found between the different groups of patients regarding baseline findings.

\section{Operative Results: - Tables 1 and 2}

The operative time was $\sim 125(100-150)$ minutes in the extended right hemicolectomy group, and 105 (100150) minutes in both the extended left hemicolectomy group and the segmental resection of the splenic flexure group $(p<0.001)$.

We performed multiorgan resection in $7.5 \%$ of all included patients in the extended right hemicolectomy group, in $7.5 \%$ of the extended left hemicolectomy group, and in $10.0 \%$ of the segmental resection of the splenic flexure group.

We have reported no colon perforation from the cancer or from the surgical procedures.

We have found no statistically significant differences between the three included groups regarding operative findings (-Table 2).

\section{Postoperative Results}

The duration of the postoperative hospital stay was 7 (5-9) days for most patients.

The immediate postoperative period was uneventful and there were no significant differences among the studied groups regarding postoperative complications (-Table $\mathbf{2}$ ).

\section{Histopathological Results}

Most cases were diagnosed as conventional adenocarcinoma of the colon (NOS) while of patients was diagnosed with mucoid carcinoma.

Cancer-free surgical margins were found in 114 (95.0\%) patients, correct lymphadenectomy with number of dissected lymph nodes was found in all patients, and there were no significant differences among the studied groups regarding histopathological findings.

The number of dissected lymph nodes was $24(10-28)$ in the extended right hemicolectomy group, 20 (10-27) in the 
Table 1 Correlations between the three studied surgical techniques regarding demographic and operative findings of included patients

\begin{tabular}{|c|c|c|c|c|c|c|c|c|c|c|}
\hline \multirow{3}{*}{\multicolumn{2}{|c|}{ Clinical characteristics of the patients }} & \multicolumn{6}{|c|}{ Management surgical techniques } & \multirow{2}{*}{\multicolumn{2}{|c|}{ Total }} & \multirow[t]{3}{*}{ p-value } \\
\hline & & \multicolumn{2}{|c|}{$\begin{array}{l}\text { Segmental } \\
\text { resection }\end{array}$} & \multicolumn{2}{|c|}{$\begin{array}{l}\text { Extended } \\
\text { right hemi- } \\
\text { colectomy }\end{array}$} & \multicolumn{2}{|c|}{$\begin{array}{l}\text { Left hemi- } \\
\text { colectomy }\end{array}$} & & & \\
\hline & & $n$ & $\%$ & $n$ & $\%$ & $n$ & $\%$ & $n$ & $\%$ & \\
\hline \multicolumn{2}{|l|}{ Age (years old)* } & \multicolumn{2}{|c|}{$55(29-80)$} & \multicolumn{2}{|c|}{$55(29-80)$} & \multicolumn{2}{|c|}{$55(29-80)$} & \multicolumn{2}{|c|}{$55(29-80)$} & 1 \\
\hline \multirow[t]{2}{*}{ Gender } & Female & 14 & $35.0 \%$ & 14 & 1 & 14 & $35.0 \%$ & 42 & $35.0 \%$ & \multirow[t]{2}{*}{1} \\
\hline & Male & 26 & $65.0 \%$ & 26 & 1 & 26 & $65.0 \%$ & 78 & $65.0 \%$ & \\
\hline \multirow[t]{2}{*}{ Tumor size } & $\leq 5 \mathrm{~cm}$ & 25 & $62.5 \%$ & 25 & 1 & 25 & $62.5 \%$ & 75 & $62.5 \%$ & \multirow[t]{2}{*}{1} \\
\hline & $>5 \mathrm{~cm}$ & 15 & $37.5 \%$ & 15 & $37.5 \%$ & 15 & $37.5 \%$ & 45 & $37.5 \%$ & \\
\hline \multirow[t]{2}{*}{$\begin{array}{l}\text { Histopathological } \\
\text { subtype }\end{array}$} & $\begin{array}{l}\text { Conventional } \\
\text { adeno carcinoma }\end{array}$ & 30 & $75.0 \%$ & 29 & $72.5 \%$ & 29 & $72.5 \%$ & 88 & $73.3 \%$ & \multirow[t]{2}{*}{0.958} \\
\hline & Mucoid carcinoma & 10 & $25.0 \%$ & 11 & $27.5 \%$ & 11 & $27.5 \%$ & 32 & $26.7 \%$ & \\
\hline \multirow[t]{3}{*}{ DUKE stage } & A & 12 & $30.0 \%$ & 12 & $30.0 \%$ & 12 & $30.0 \%$ & 36 & $30.0 \%$ & \multirow[t]{3}{*}{1} \\
\hline & $\mathrm{B}$ & 11 & $27.5 \%$ & 11 & $27.5 \%$ & 11 & $27.5 \%$ & 33 & $27.5 \%$ & \\
\hline & $C$ & 17 & $42.5 \%$ & 17 & $42.5 \%$ & 17 & $42.5 \%$ & 51 & $42.5 \%$ & \\
\hline \multirow[t]{3}{*}{ Stage } & I & 12 & $30.0 \%$ & 12 & $30.0 \%$ & 12 & $30.0 \%$ & 36 & $30.0 \%$ & \multirow[t]{3}{*}{0.771} \\
\hline & II & 17 & $42.5 \%$ & 14 & $35.0 \%$ & 12 & $30.0 \%$ & 43 & $35.8 \%$ & \\
\hline & III & 11 & $27.5 \%$ & 14 & $35.0 \%$ & 16 & $40.0 \%$ & 41 & $34.2 \%$ & \\
\hline \multirow[t]{2}{*}{ Lymph node metastasis } & No & 29 & $72.5 \%$ & 26 & $65.0 \%$ & 24 & $60.0 \%$ & 79 & $65.8 \%$ & \multirow[t]{2}{*}{0.495} \\
\hline & Yes & 11 & $27.5 \%$ & 14 & $35.0 \%$ & 16 & $40.0 \%$ & 41 & $34.2 \%$ & \\
\hline \multicolumn{2}{|c|}{ Number of lymph nodes harvested* } & \multicolumn{2}{|c|}{$15(9-20)$} & \multicolumn{2}{|c|}{$24(10-28)$} & \multicolumn{2}{|c|}{$20(10-27)$} & \multicolumn{2}{|c|}{$20(9-28)$} & $<0.001^{£}$ \\
\hline \multirow[t]{3}{*}{ Grade } & 1 & 11 & $27.5 \%$ & 11 & $27.5 \%$ & 11 & $27.5 \%$ & 33 & $27.5 \%$ & \multirow[t]{3}{*}{1} \\
\hline & II & 26 & $65.0 \%$ & 26 & $65.0 \%$ & 26 & $65.0 \%$ & 78 & $65.0 \%$ & \\
\hline & III & 3 & $7.5 \%$ & 3 & $7.5 \%$ & 3 & $7.5 \%$ & 9 & $7.5 \%$ & \\
\hline Multiorgan resection & No & 36 & $90.0 \%$ & 37 & $92.5 \%$ & 37 & $92.5 \%$ & 110 & $91.7 \%$ & 0.897 \\
\hline & Yes & 4 & $10.0 \%$ & 3 & $7.5 \%$ & 3 & $7.5 \%$ & 10 & $8.3 \%$ & \\
\hline Margin status & R0 & 38 & $95.0 \%$ & 38 & $95.0 \%$ & 38 & $95.0 \%$ & 114 & $95.0 \%$ & 1 \\
\hline & R1 & 2 & $5.0 \%$ & 2 & $5.0 \%$ & 2 & $5.0 \%$ & 6 & $5.0 \%$ & \\
\hline
\end{tabular}

All variables were compared using the chi-squared $\mathrm{X}^{2}$ test, except $\left(^{*}\right)$ in which the Mann-Whitney test was used.

${ }^{E}$ post-hoc analysis for segmental resection versus extended right hemicolectomy, segmental resection versus left hemicolectomy, and left hemicolectomy versus extended right hemicolectomy (all $p<0.001$ )

extended left hemicolectomy group, and $15(9-20)$ in the segmental resection group (-Table $\mathbf{3}$ ).

There was a statistically significant difference in the number of dissected lymph nodes among the 3 studied groups, with a higher number of lymph nodes in the extended right hemicolectomy group $(p<0.001)$ (-Table 2).

\section{Oncologic and Follow-up Data: - Table 3, - Fig. 1}

The follow up time was of $\sim 36$ months.

During the follow-up period, we have found no statistically significant differences among groups regarding local recurrence, distant recurrence, disease progression, recurrence free survival rate, progression free survival rate, and overall survival rate.

\section{Discussion}

There is no established method of management of splenic flexure cancer due to incomplete understanding of dual lymphatic drainage of this location, which is related to both the superior and the inferior mesenteric vessels. ${ }^{3,4,13}$

Griffiths $^{14}$ showed that the splenic flexure region is supplied by the terminal branches of the left colic artery in $89 \%$ of cases and by the middle colic branch of the superior mesenteric artery in $11 \%$.

Nakagoe et al. ${ }^{15}$ showed that most lymph nodes that proved to be positive for metastatic spread were found to be located along the left colic artery and the paracolic arcade. Vasey et al. ${ }^{16}$ concluded that splenic flexure lymphatic drainage was directed toward the left colic vessels in $96 \%$ 
Management Surgical Approaches of Splenic Flexure Colon Cancer El-Hendawy et al. 51

Table 2 Correlations between the three studied surgical techniques regarding postoperative findings of included patients

\begin{tabular}{|c|c|c|c|c|c|c|c|c|c|c|}
\hline \multirow{3}{*}{\multicolumn{2}{|c|}{ Postoperative data }} & \multicolumn{6}{|c|}{ Surgical management technique } & \multirow{2}{*}{\multicolumn{2}{|c|}{ Total }} & p-value \\
\hline & & \multicolumn{2}{|c|}{$\begin{array}{l}\text { Segmental } \\
\text { resection }\end{array}$} & \multicolumn{2}{|c|}{$\begin{array}{l}\text { Extended } \\
\text { right hemi- } \\
\text { colectomy }\end{array}$} & \multicolumn{2}{|c|}{$\begin{array}{l}\text { Left hemico- } \\
\text { lectomy }\end{array}$} & & & \\
\hline & & $n$ & $\%$ & $n$ & $\%$ & $n$ & $\%$ & $n$ & $\%$ & \\
\hline \multicolumn{2}{|l|}{ Duration of hospital stay, days* } & \multicolumn{2}{|c|}{$7(5-9)$} & \multicolumn{2}{|c|}{$7(5-9)$} & \multicolumn{2}{|c|}{$7(5-9)$} & \multicolumn{2}{|c|}{$7(5-9)$} & 0.514 \\
\hline \multirow[t]{5}{*}{ Duration of hospital stay } & 5 & 7 & $17.5 \%$ & 5 & $12.5 \%$ & 4 & $10.0 \%$ & 16 & $13.3 \%$ & \multirow[t]{5}{*}{0.963} \\
\hline & 6 & 11 & $27.5 \%$ & 9 & $22.5 \%$ & 8 & $20.0 \%$ & 28 & $23.3 \%$ & \\
\hline & 7 & 9 & $22.5 \%$ & 10 & $25.0 \%$ & 12 & $30.0 \%$ & 31 & $25.8 \%$ & \\
\hline & 8 & 7 & $17.5 \%$ & 9 & $22.5 \%$ & 10 & $25.0 \%$ & 26 & $21.7 \%$ & \\
\hline & 9 & 6 & $15.0 \%$ & 7 & $17.5 \%$ & 6 & $15.0 \%$ & 19 & $15.8 \%$ & \\
\hline \multirow[t]{2}{*}{ 30-day morbidity } & No & 38 & $95.0 \%$ & 38 & $95.0 \%$ & 38 & $95.0 \%$ & 114 & $95.0 \%$ & \multirow[t]{2}{*}{1} \\
\hline & Yes & 2 & $5.0 \%$ & 2 & $5.0 \%$ & 2 & $5.0 \%$ & 6 & $5.0 \%$ & \\
\hline \multirow[t]{2}{*}{ 30-day mortality } & No & 39 & $97.5 \%$ & 39 & $97.5 \%$ & 39 & $97.5 \%$ & 117 & $97.5 \%$ & \multirow[t]{2}{*}{1} \\
\hline & Yes & 1 & $2.5 \%$ & 1 & $2.5 \%$ & 1 & $2.5 \%$ & 3 & $2.5 \%$ & \\
\hline \multicolumn{2}{|l|}{ Operative time (minutes) } & \multicolumn{2}{|c|}{$105(90-150)$} & \multicolumn{2}{|c|}{$125(100-150)$} & \multicolumn{2}{|c|}{$105(100-150)$} & \multicolumn{2}{|c|}{$110(90-150)$} & $<0.001^{f}$ \\
\hline \multirow[t]{2}{*}{ Operative complications } & 0 & 38 & $95.0 \%$ & 38 & $95.0 \%$ & 38 & $95.0 \%$ & 114 & $95.0 \%$ & \multirow[t]{2}{*}{1} \\
\hline & 1 & 2 & $5.0 \%$ & 2 & $5.0 \%$ & 2 & $5.0 \%$ & 6 & $5.0 \%$ & \\
\hline \multirow[t]{2}{*}{ Postoperative complications } & 0 & 35 & $87.5 \%$ & 36 & $90.0 \%$ & 36 & $90.0 \%$ & 107 & $89.2 \%$ & \multirow[t]{2}{*}{0.917} \\
\hline & 1 & 5 & $12.5 \%$ & 4 & $10.0 \%$ & 4 & $10.0 \%$ & 13 & $10.8 \%$ & \\
\hline \multirow[t]{2}{*}{ Relapse } & No & 32 & $80.0 \%$ & 32 & $80.0 \%$ & 32 & $80.0 \%$ & 96 & $80.0 \%$ & \multirow[t]{2}{*}{1} \\
\hline & Yes & 8 & $20.0 \%$ & 8 & $20.0 \%$ & 8 & $20.0 \%$ & 24 & $20.0 \%$ & \\
\hline \multirow[t]{2}{*}{ Death } & No & 36 & $90.0 \%$ & 35 & $87.5 \%$ & 36 & $90.0 \%$ & 107 & $89.2 \%$ & \multirow[t]{2}{*}{0.917} \\
\hline & Yes & 4 & $10.0 \%$ & 5 & $12.5 \%$ & 4 & $10.0 \%$ & 13 & $10.8 \%$ & \\
\hline
\end{tabular}

All variables were compared using the chi-squared $\mathrm{X}^{2}$ test, except $\left(^{*}\right)$ in which the Mann-Whitney test was used.

${ }_{\text {E }}$ post-hoc analysis for segmental resection versus extended right hemicolectomy, and left hemicolectomy versus extended right hemicolectomy (all $p<0.001$ ); however, segmental resection versus left hemicolectomy $p=0.464$,

Table 3 Correlations between the three studied surgical techniques regarding progression and survival outcome of included patients

\begin{tabular}{|c|c|c|c|c|c|c|c|c|c|c|}
\hline \multirow[t]{2}{*}{ Survival analysis } & \multirow[t]{2}{*}{ Total $(n)$} & \multirow[t]{2}{*}{ Events $(n)$} & \multicolumn{2}{|c|}{ Censored } & \multirow[t]{2}{*}{$\begin{array}{l}\text { Survival } \\
\text { rate\% }\end{array}$} & \multirow[t]{2}{*}{ Sig. } & \multicolumn{2}{|c|}{$\begin{array}{l}\text { Survival } \\
\text { time, months }\end{array}$} & \multicolumn{2}{|l|}{$95 \% \mathrm{Cl}$} \\
\hline & & & $n$ & Percent & & & Mean & Standard error & $\begin{array}{l}\text { Lower } \\
\text { boundary }\end{array}$ & $\begin{array}{l}\text { Upper } \\
\text { boundary }\end{array}$ \\
\hline \multicolumn{11}{|l|}{ Relapse-free survival } \\
\hline Segmental resection & 40 & 8 & 32 & $80.00 \%$ & 0.8 & \multirow[t]{3}{*}{0.987} & 31.85 & 1.335 & 29.233 & 34.467 \\
\hline $\begin{array}{l}\text { Extended right } \\
\text { hemicolectomy }\end{array}$ & 40 & 8 & 32 & $80.00 \%$ & 0.8 & & 31.15 & 1.537 & 28.137 & 34.163 \\
\hline Left hemicolectomy & 40 & 8 & 32 & $80.00 \%$ & 0.8 & & 31.15 & 1.537 & 28.137 & 34.163 \\
\hline Overall & 120 & 24 & 96 & $80.00 \%$ & 0.8 & & 31.383 & 0.851 & 29.715 & 33.051 \\
\hline \multicolumn{11}{|l|}{ Overall survival } \\
\hline Segmental resection & 40 & 4 & 36 & $90.00 \%$ & 0.9 & \multirow[t]{3}{*}{0.909} & 34.2 & 0.868 & 32.499 & 35.901 \\
\hline $\begin{array}{l}\text { Extended right } \\
\text { hemicolectomy }\end{array}$ & 40 & 5 & 35 & $87.50 \%$ & 0.875 & & 33.325 & 1.128 & 31.115 & 35.535 \\
\hline Left hemicolectomy & 40 & 4 & 36 & $90.00 \%$ & 0.895 & & 34 & 0.947 & 32.143 & 35.857 \\
\hline Overall & 120 & 13 & 107 & $89.20 \%$ & 0.89 & & 33.842 & 0.571 & 32.723 & 34.961 \\
\hline
\end{tabular}

Abbreviation: $\mathrm{Cl}$, confidence interval.

*Median was not reached. 

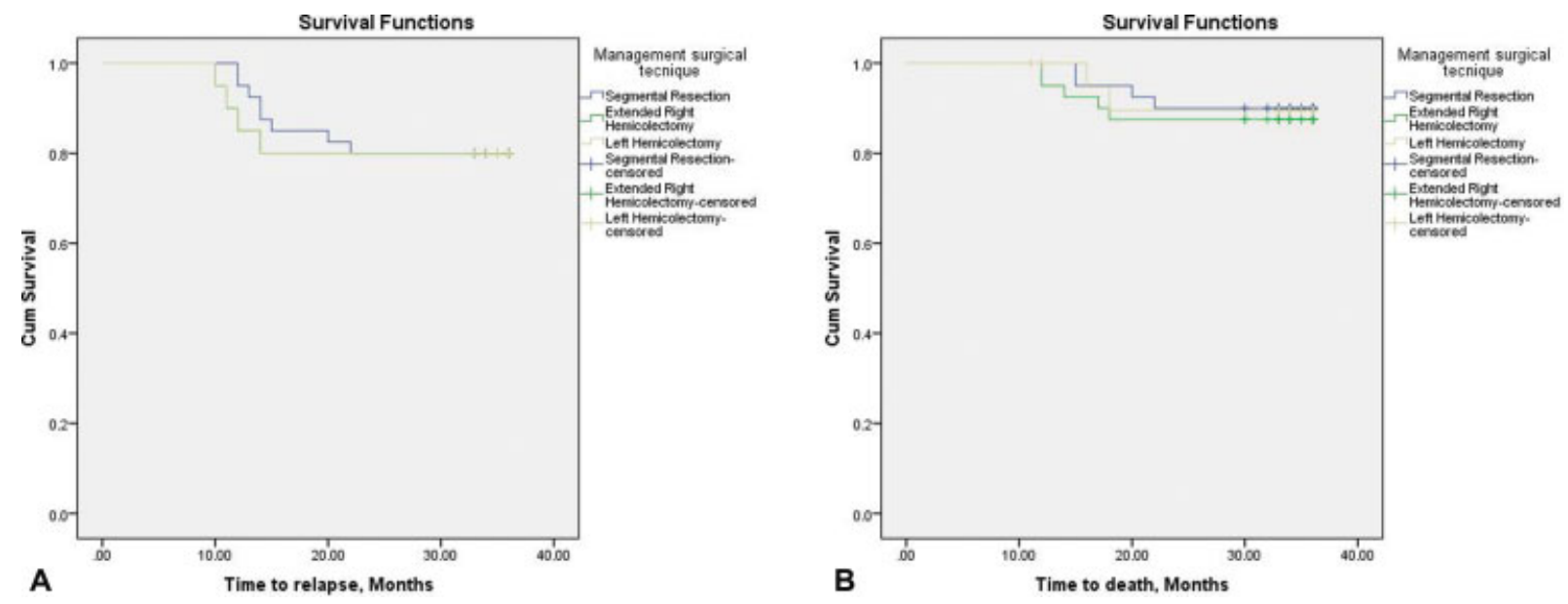

Fig. 1 Survival findings of included patients: (A) time to recurrence and recurrence-free survival rate, (B) time to death and overall survival rate.

of the patients. Some surgeons stated that performing extended hemicolectomy is the best method of management of splenic flexure cancer and consider segmental resection as being less radical to ensure complete removal of all lymph nodes along the branches of the superior mesenteric vessels. $^{4,17,18}$ Other surgeons restricted performing segmental resection for older patients, for patients with comorbid conditions, and as a palliative measure for cases with extensive disease. ${ }^{19}$ Other authors showed that extended resection has benefits on survival and is not necessary for all cases. ${ }^{3,20}$ Removal of at least 12 lymph nodes in surgically excised colon cancer is sufficient to ensure radicalism, ${ }^{21}$ which is associated with complete mesocolic excision. ${ }^{11,22}$

In the present study, we assessed the oncological outcomes of patients with splenic flexure cancer managed by three different surgical approaches - segmental resection, extended left or left hemicolectomy - to detect the best surgical approach of management of this anatomical variant.

Although extended right hemicolectomy produced a higher number of dissected lymph nodes, patients with $>12$ dissected lymph nodes were similar between all the 3 groups we have found no statistically significant differences among groups regarding local recurrence, distant recurrence, disease progression, recurrence free survival rate, progression free survival rate, and overall survival rate. Rega et al. ${ }^{1}$ performed the first study that compared the three surgical approaches in the management of splenic flexure cancer and found nearly similar results. Our study included a large number of patients operated in more than one hospital, so its results could prove the feasibility of performing segmental resection better than extended resections, with shorter operative time and similar postoperative and long-term outcomes.

Regarding the surgical management of splenic flexure cancer, previous studies have compared only extended right colon resection with extended left colon resection, but they did not clarify long-term and follow-up oncological outcomes. ${ }^{18,23,24}$

Martínez-Pérez et al. $^{23}$ showed that the extent of the surgical procedure does not affect the resection quality or the postoperative outcomes.
With results that were nearly similar to ours, Rega et al. ${ }^{1}$ showed that the number of dissected lymph nodes and the rate of negative margins were similar in the three studied groups.

The large number of dissected lymph nodes in the group of patients who were managed by extended right hemicolectomy was due to more extent of colon resection colon with least 3 colonic vascular branches, as has also been reported by other authors. ${ }^{24}$

In the present study, we made multiorgan resection in included patients which is indicated to made RO in some cases with large tumor size, we found no statistically significant differences among groups regarding the degree of organ resection. Regarding the degree and number of cases that underwent organ resection, similar results were reported by Rega et al. ${ }^{1}$.

Additionally, Perrakis et al. ${ }^{25}$ showed that the rationale for performing splenectomy alone or in addition to distal pancreasectomy is the presence of large number of metastatic lymph nodes in the greater curvature of the stomach, in the head of the pancreas, or in the inferior part of the pancreas.

Regarding operative safety, we have observed no significant difference in the safety, by complication rates, or in the severity of complications among the three studied techniques.

Moreover, we found no statistically significant differences between groups regarding the survival rates of the patients who were followed-up.

Generally, for the adequate management of colon cancer sharp dissection of tissue planes and giving resected tissues having intact mesocolic fascia that surrounded tumor draining lymphatics.

Performing segmental resection of carcinoma of the splenic flexure allows the removal of the left colic, left branch of middle colic lymphatics, ensuring removal of most of lymphatic drainage of colon cancer located in the splenic flexure.

Multiorgan resection was performed in 3 (7.5\%) of all included patients of the extended right hemicolectomy group, in 3 patients (7.5\%) of the extended left hemicolectomy group, and in 4 patients (10.0\%) of the segmental resection of the splenic flexure group. 
Due to the prospective nature of the present study, we selected randomly the procedure to be performed.

\section{Conclusion}

Collectively, we showed that segmental resection of splenic flexure is surgically and clinically suitable for the adequate management of operable cases of carcinoma of the splenic flexure in Egyptian patients, and that the clinical, surgical, survival or oncological benefits of extended surgery do not surpass those of segmental resection. Moreover, segmental resection allows adequate removal of lymph drainage.

\section{Strengths of the Present Study}

One of the strengths of the present study is its prospective nature. Another is that the study was performed on a large number of Egyptian patients with cancer of the splenic flexure, which is a single anatomical subtype of colon cancer. Also, the long follow-up period, which allowed adequate reporting of the results.

Limitations of the Present Study

Its monocenter nature.

\section{Recommendations}

We recommend performing large scale, multicenter, prospective, and randomized studies to prove our data regarding the surgical management of splenic flexure cancer.

\section{Conflict of Interests}

The authors have no conflict of interests to declare.

\section{References}

1 Rega D, Pace U, Scala D, et al. Treatment of splenic flexure colon cancer: a comparison of three different surgical procedures: Experience of a high volume cancer center. Sci Rep 2019;9(01):10953

2 Milone M, Angelini P, Berardi G, et al. Intracorporeal versus extracorporeal anastomosis after laparoscopic left colectomy for splenic flexure cancer: results from a multi-institutional audit on 181 consecutive patients. Surg Endosc 2018;32(08):3467-3473

3 Shaikh IA, Suttie SA, Urquhart M, Amin AI, Daniel T, Yalamarthi S. Does the outcome of colonic flexure cancers differ from the other colonic sites? Int J Colorectal Dis 2012;27(01):89-93

4 Odermatt M, Siddiqi N, Johns R, et al. Short- and long-term outcomes for patients with splenic flexure tumours treated by left versus extended right colectomy are comparable: a retrospective analysis. Surg Today 2014;44(11):2045-2051

5 Chong CS, Huh JW, Oh BY, et al. Operative Method for Transverse Colon Carcinoma: Transverse Colectomy Versus Extended Colectomy. Dis Colon Rectum 2016;59(07):630-639

6 van Rongen I, Damhuis RA, van der Hoeven JA, Plaisier PW. Comparison of extended hemicolectomy versus transverse colectomy in patients with cancer of the transverse colon. Acta Chir Belg 2013;113(02):107-111
7 UICC TNM classification of malignant tumors. 7th ed. New York: John Wiley \& Sons; 2009

8 Feig BW, Ching CD. The MD Anderson Surgical Oncology Handbook, Department of Surgical Oncology. (eds University of Texas MD Anderson Cancer Center) Philadelphia, P. A.: Lippicott Williams \& Wilkins; 2011

9 Kim JW, Kim JY, Kang BM, Lee BH, Kim BC, Park JH. Short- and long-term outcomes of laparoscopic surgery vs open surgery for transverse colon cancer: a retrospective multicenter study. OncoTargets Ther 2016;9:2203-2209

10 Sakorafas GH, Zouros E, Peros G. Applied vascular anatomy of the colon and rectum: clinical implications for the surgical oncologist. Surg Oncol 2006;15(04):243-255

11 West NP, Kobayashi H, Takahashi K, et al. Understanding optimal colonic cancer surgery: comparison of Japanese D3 resection and European complete mesocolic excision with central vascular ligation. J Clin Oncol 2012;30(15):1763-1769

12 Otchy D, Hyman NH, Simmang C, et al; Standards Practice Task Force American Society of Colon and Rectal Surgeons. Practice parameters for colon cancer. Dis Colon Rectum 2004;47(08): 1269-1284

13 Bourgouin S, Bège $\mathrm{T}$, Lalonde $\mathrm{N}$, et al. Three-dimensional determination of variability in colon anatomy: applications for numerical modeling of the intestine. J Surg Res 2012;178(01):172-180

14 Griffiths JD. Surgical anatomy of the blood supply of the distal colon. Ann R Coll Surg Engl 1956;19(04):241-256

15 Nakagoe T, Sawai T, Tsuji T, et al. Surgical treatment and subsequent outcome of patients with carcinoma of the splenic flexure. Surg Today 2001;31(03):204-209

16 Vasey CE, Rajaratnam S, O'Grady G, Hulme-Moir M. Lymphatic Drainage of the Splenic Flexure Defined by Intraoperative Scintigraphic Mapping. Dis Colon Rectum 2018;61(04):441-446

17 Pisani Ceretti A, Maroni N, Sacchi M, et al. Laparoscopic colonic resection for splenic flexure cancer: our experience. BMC Gastroenterol 2015;15(15):76

18 de'Angelis N, Hain E, Disabato M, et al. Laparoscopic extended right colectomy versus laparoscopic left colectomy for carcinoma of the splenic flexure: a matched case-control study. Int J Colorectal Dis 2016;31(03):623-630

19 Shen SS, Haupt BX, Ro JY, Zhu J, Bailey HR, Schwartz MR. Number of lymph nodes examined and associated clinicopathologic factors in colorectal carcinoma. Arch Pathol Lab Med 2009;133(05): 781-786

$20 \mathrm{Kim}$ CW, Shin US, Yu CS, Kim JC. Clinicopathologic characteristics, surgical treatment and outcomes for splenic flexure colon cancer. Cancer Res Treat 2010;42(02):69-76

21 Dotan E, Cohen SJ. Challenges in the management of stage II colon cancer. Semin Oncol 2011;38(04):511-520

22 Weber K, Merkel S, Perrakis A, Hohenberger W. Is there a disadvantage to radical lymph node dissection in colon cancer? Int J Colorectal Dis 2013;28(02):217-226

23 Martínez-Pérez A, Brunetti F, Vitali GC, Abdalla S, Ris F, de'Angelis $\mathrm{N}$. Surgical Treatment of Colon Cancer of the Splenic Flexure: A Systematic Review and Meta-analysis. Surg Laparosc Endosc Percutan Tech 2017;27(05):318-327

24 Gravante G, Elshaer M, Parker R, et al. Extended right hemicolectomy and left hemicolectomy for colorectal cancers between the distal transverse and proximal descending colon. Ann R Coll Surg Engl 2016;98(05):303-307

25 Perrakis A, Weber K, Merkel S, et al. Lymph node metastasis of carcinomas of transverse colon including flexures. Consideration of the extramesocolic lymph node stations. Int J Colorectal Dis 2014;29(10):1223-1229 